\title{
Active phytochemicals present in the Guava Tree (Psidium Guajava) leaf Extracts that grow in Uganda.
}

\author{
Journal of Ethnopharmacology@sjhr-Africa \\ David Serunjogia,1,2 \\ a Faculty of Health Sciences, Uganda Martyrs University, \\ Kampala, Uganda
}

\begin{abstract}
Background: The Guava tree is small in the myrtle family (Myrtaceae), native to Mexico, Central America, the Caribbean, and northern South America. It contains a high content of organic and inorganic compounds like secondary metabolites such as antioxidants, polyphenols, antiviral compounds, and anti-inflammatory compounds. Such chemicals are produced by plants through primary or secondary metabolism whereas Guava products have been used as a source of medicine and while they have proved to work effectively, little is known about the composition of such plant origin products from Uganda.

Methodology: The maceration method of extraction was used to obtain the guava extract. The leaves were crushed into a powder using a blender and $20 \mathrm{~g}$ of the powder was added into differently labeled beakers containing $100 \mathrm{mls}$ of distilled water and $100 \mathrm{mls}$ of increasing concentration of methanol from $30 \%, 50 \%$, and $70 \%$. The analysis involved Saponins, Phenols and Tannins, Terpenoids, Flavonoids, and Glycosides, and Laboratory tests are done included the Ferric Chloride test, Shinoda test, Salkowski test, Concentrate $\mathrm{H} 2 \mathrm{SO} 4$ test, and Foam test.

Results and discussion: Phytochemicals (Saponins, Phenols and Tannins, Terpenoids, Flavonoids, and Glycosides) are present in the leaves of the guava tree (Psidium guajava) that grows in Uganda. Psidium guajava extract obtained using distilled water contained all the phytochemicals tested apart from terpenoids which showed a negative test result. Methanol of increasing concentrations can also be used to extract phytochemicals from the leaves.

Conclusions and recommendations: It's now evident that the Guava tree that grows in Uganda contains phytochemicals (secondary metabolites). Water and methanol of 30\%,50\%, and $70 \%$ can be used for extraction. Future detailed studies in Africa should focus on the purification of these active secondary metabolites and also determine their concentration. Other parts of the plant such as its bark, roots, and fruits need to be studied.
\end{abstract}

\section{Introduction:}

The Guava tree is a common tropical fruit cultivated in many tropical and subtropical regions (Psidium guajava (common guava, lemon guava) is a small tree in the myrtle family (Myrtaceae), native to Mexico, Central America, the Caribbean, and northern South America Morton, et al., (2015) The most frequently eaten species, and the one often simply referred to as "the guava", is the apple guava (Psidium guajava).

\footnotetext{
${ }^{1}$ Corresponding author.

2E-mail: serunjogidavid16@gmail.com
} 
According to Naseer et al., (2018), Guava contains a high content of organic and inorganic compounds like secondary metabolites like antioxidants, polyphenols, antiviral compounds, anti-inflammatory compounds some of which have shown to assist in curing cancerous cells and prevent skin aging before time. Guava leaves contain many compounds that act as fungistatic and bacteriostatic agents. These contain a high content of important antioxidants and have a radio-protective ability.

Phytochemicals are chemicals produced by plants through primary or secondary metabolism (Molyneux et al., 2007 and Harborne et al., 1999). Phytochemicals play a role in plant growth or defense against competitors, pathogens, or predators (Molyneux et al., 2007) and due to this ability, they have attracted a lot of attention from researchers.

In Africa, plant origin products have been used as a source of medicine and while they have proved to work effectively, little is known about the composition of such plant origin products. Early studies outside Uganda have studied the guava tree and have confirmed the presence of phytochemicals. This is, however, missing in Uganda. The guava tree is considered one of the valuable trees in traditional medicine and despite this fact, little is documented about the active phytochemicals that are present in the local species and the best way to extract them out of the leaves. This study aimed to detect the presence of such phytochemicals in the guava trees that grow in Uganda and the different extraction methods that can be used.

\section{Data Collection Methods}

\section{Methodology: 3 Materials and Methods}

Instruments:

The tools used in the study included analytical scale, blender, sieves, desiccators, Petridis, stir bar, pipettes, flask filter paper, aluminum foil, vortex, incubator, centrifuge, and platform shaker, sieve, stop the clock, cock borer, and labeling pencil.

Material:

Materials used in the extraction included the guava leaves, distilled water, technical ethanol of $30 \%$, $50 \%$, and $70 \%$, sodium carbonate( $\mathrm{Na} 2 \mathrm{CO} 3$ ) $7 \%$, iron (iii) chloride( $\mathrm{FeCl} 3) 1 \%$, magnesium ribbon fragments, concentrated hydrochloric acid, chloroform, concentrated Sulphuric acid, Glacial acetic acid.

\section{Preparation of the plant extract}

The guava leaves were collected from a plantation near the zika forest and samples were put in a bag and transferred to the university laboratory where it was identified. The guava leaves were then washed using tap water, left to dry, and then weighted, its average weights were measured and recorded. The average wet mass was $2.5 \mathrm{~g}$ for each leaf. The guava leaves were left to dry at $29^{\circ} \mathrm{C}$ for 7 days and the average weight was $0.83 \mathrm{~g}$ and this was captured as dry mass.

\section{Extraction method}

The maceration method of extraction was used to obtain the guava extract. The leaves were crushed into a powder using a blender and $20 \mathrm{~g}$ of the powder was added into differently labeled beakers containing $100 \mathrm{mls}$ of distilled water and $100 \mathrm{mls}$ of increasing concentration of methanol from $30 \%, 50 \%$, and $70 \%$.

The powder was then mixed with the solvents using a vortex for 2 minutes and the flasks were covered with aluminum foil and left to stand at the working bench for 3 days at $29^{\circ} \mathrm{C}$. The flasks were then shaken vigorously after the 3 days of soaking in a solvent, then, the mixtures were transferred to $4 \mathrm{~mL}$ tubes and centrifuged for $10 \mathrm{~min}$ at $4,000 \mathrm{rpm}$ at $29^{\circ} \mathrm{C}$. The supernatant was collected and stored at $4^{\circ} \mathrm{C}$ until use.

\section{Detection of the active ingredients}

The analysis involved Saponins, Phenols, and Tannins, Terpenoids, Flavonoids, and Glycosides.

\section{Phenols and tannins (Ferric Chloride Test).}

The crude extract was boiled with $5 \mathrm{ml}$ of $45 \%$ solution of ethanol for 5 minutes. Each of the mixtures is cooled and filtered then used to do the test.

To the $2 \mathrm{mls}$ of extract added in a test tube, $2 \mathrm{mls}$ of $2 \%$ solution of Iron(III) chloride (FeCl3) was added. 
Table 1. shows the results obtained from the detection of the active phytochemicals present in the guava extract.

\begin{tabular}{lllll}
\hline & Water extract & $\mathbf{3 0 \% \text { methanol }}$ & $\mathbf{5 0 \% \text { methanol }}$ & $\mathbf{7 0 \% \text { methanol }}$ \\
Saponins & Positive & Positive & Positive & Positive \\
Phenols and Tannins & Positive & Positive & Positive & Positive \\
Terpenoids & Negative & Positive & Positive & Positive \\
Flavonoids & Positive & Positive & Positive & Positive \\
glycosides & Positive & Positive & Positive & Positive \\
\hline
\end{tabular}

To the $2 \mathrm{mls}$ of extracts in the test tube, magnesium ribbon fragments were added plus concentrated hydrochloric acid droop wise.

\section{Terpenoids (Salkowski test).}

$2 \mathrm{mls}$ of extract in the test tube were mixed with $2 \mathrm{mls}$ of chloroform then $2 \mathrm{mls}$ of concentrated Sulphuric acid was added and shaken gently.

\section{Glycoside (Concentrate H2SO4Test).}

To $2 \mathrm{mls}$ of extract in the test tube, $2 \mathrm{mls}$ of glacial acetic acid plus 2 droops of $2 \%$ iron (III) chloride plus $2 \mathrm{mls}$ of concentrated. Sulphuric acid was added.

\section{Saponins (Foam Test).}

$2 \mathrm{mls}$ of each extract was added to the test tube and vigorously shaken.

\section{Results and discussion}

Analysis of the phytochemicals present

The table below shows the results of the quantitative tests done to detect the presence of the active phytochemicals present using the different extraction solvents.

\section{Phenols and tannins results (Ferric Chloride Test)}

Observation- the formation of a blue-green or black coloration indicated the presence of phenols and tannins.

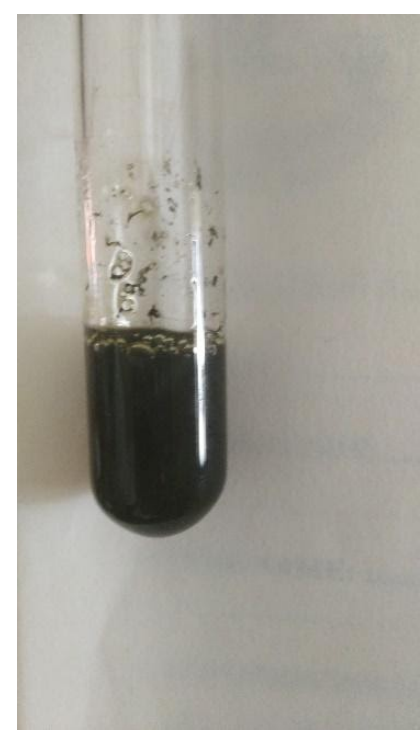

Figure 1. showing the blue green or black coloration indicating presence of phenols and tannins

\section{Flavonoids test results:}

Observation- the formation of a pink coloration indicated the presence of flavonoids. 


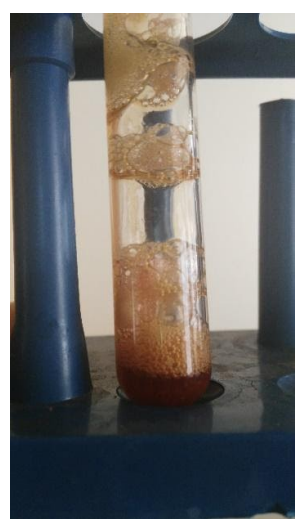

Figure 2. shows the orange, red, pink coloration indicating presence of flavonoids.

Observation- the formation of a reddish brown coloration of the interphase indicated the presence of terpenoids.

Figure 3. shows a reddish brown coloration

\section{Glycosides test results}

Observation- the formation of a brown ring indicated the presence of glycosides.

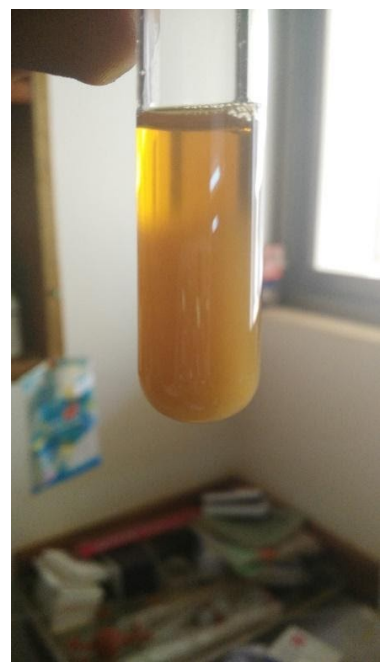

Figure 4. shows the brown rings an indication of glycosides

\section{Saponins test results}


Observation The formation of stable foam was an indicator that Saponins were present.

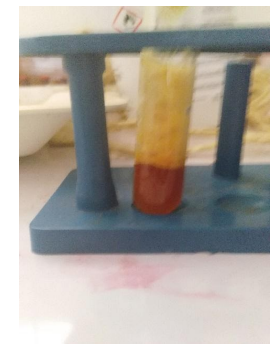

Figure 5. showing the formation of a stable foam

\section{Discussion}

Findings of similar investigations have reported that there are active phytochemicals in the different plant parts. According to a study by Senguttuvan et al.,(2014) showed that Glycosides, Flavonoids, Phenols, Tannins, Saponins are highly present in the extract of leaves obtained from $\mathrm{H}$. radicata and Terpenoids are present in moderate amounts when methanol and water are used as the extraction solvents. The results of the current study also have shown that the same phytochemicals are present in the leaves of the guava tree (Psidium guajava). Senguttuvanm et al., (2014) results showed that water as the extraction medium did not extract Glycosides, Phenols, Tannins, and Saponins from $\mathrm{H}$. radicata leaves. However, the results from the present study show that the Psidium guajava extract obtained using distilled water contained all the phytochemicals tested apart from terpenoids which showed a negative test result when water was used for extraction. The observations made in this study (formation of a stable foam to confirm Saponins, the formation of a pink coloration for Flavonoids, and the formation of a brown ring indicating the presence of Glycosides using Concentrate H2SO4 test) were similar to ones reported by Rahman et al., (2017) in the study were Phytochemical Screening was done on Crude Plant Extracts from Ephedra intermedia. The formation of A transient greenish to black color that indicated the presence of Tannins in this study was in agreement with a study by Sheel et al., (2014) where Phytochemical Screening of Methanolic Extract of Clerodendron infortunatum was done using the Ferric Chloride Test. The pink coloration as an indication of flavonoids in this study agrees with the results reported by Sumalatha et al., (2012) when Isolating Flavonoids of Tephrosia purpurea when the Shinoda Test was used.

\section{Conclusion and recommendations}

It's now evident that the Guava tree (Psidium guajava) that grows in Uganda contains phytochemicals (secondary metabolites). The solvents used in the extraction such as water and methanol of $30 \%, 50 \%$, and $70 \%$ can be used to extract the active phytochemicals. Future detailed studies in Africa should focus on the purification of these active secondary metabolites and also determine their concentration. This study has focused on the leaf of a guava tree, this presents other parts of the plant such as its bark, the roots, and the fruits for more studies.

\section{Acknowledgements}

I would like to appreciate the efforts of Mr. Kizito Muyonge and all his department colleagues towards this work.

\section{References:}

1. Harborne., Jeffrey B., Baxter., Herbert., Moss., \& Gerard P., (1999). "General Introduction" Phytochemical dictionary a handbook of bioactive compounds from plants (2nd ed.). London: Taylor \& Francis. p. vii.ISBN9780203483756. 
2. Molyneux., RJ .Lee, ST; Gardner., DR; Panter., KE; James, LF (2007). "Phytochemicals: the good, the bad and the ugly?"Phytochemistry. 68 (22-24): 2973-85. doi:10.1016/j.phytochem.2007.09.004. PMID 17950388

3. Morton JF (1987). "Guava" Fruits of Warm Climates. Purdue University.pp. 356-363. Retrieved 24 April 2015.

4. N. R. Sanches., D. A. G. Cortez., M. S. Schiavini., C. V. Nakamura., and B. P. D. Filho.(2005). “An evaluation of antibacterial activities of Psidium guajava (L.)," Brazilian Archives of Biology and Technology, vol. 48, no. 3, pp. 429-436, View at Google Scholar . View at Scopus

5. Naseer, S., Hussain, S., Naeem, N. (2018). "The phytochemistry and medicinal value of Psidium guajava (guava)". Clin Phytosci 4, 32. https://doi.org/10.1186/s40816-018-0093-8

6. Rahman Gul, Syed Umer Jan, Syed Faridullah, Samiullah Sherani, Nusrat Jahan, (2017) "Preliminary Phytochemical Screening, Quantitative Analysis of Alkaloids, and Antioxidant Activity of Crude Plant Extracts from Ephedra intermedia Indigenous to Balochistan", The Scientific World Journal, vol. 2017, Article ID 5873648, 7 pages,

7. Senguttuvan, J., Paulsamy, S., \& Karthika, K. (2014). "Phytochemical analysis and evaluation of leaf and root parts of the medicinal herb, Hypochaeris radicata L. for in vitro antioxidant activities". Asian Pacific journal of tropical biomedicine, 4(Suppl 1), S359-S367.

8. Sheel, D., Nisha, K., \& Kumar, J. (2014). "Preliminary Phytochemical Screening of Methanolic Extract of Clerodendron infortunatum." IOSR Journal of Applied Chemistry, 7, 10-13.

9. Sumalatha, B.I., Devprakash, Senthil Kumar G.P, Tamizh Mani, (2012) “Biological and Chemical Scienceslsolation of Flavonol of Tephrosia purpurea." Research Journal of Pharmaceutical Volume 3 Issue 3 Page No. 105. 